\title{
Micro-focus x-ray diffraction study of the columnar phase of porphyrin-based mesogens
}

\author{
${ }^{\mathrm{a}}$ Shin-Woong Kang, ${ }^{\mathrm{b}}$ Quan Li, ${ }^{\mathrm{d}}$ Brandon D. Chapman, \\ ${ }^{\mathrm{d}}$ Ron Pindak, ${ }^{\mathrm{e}}$ Julie O. Cross, ${ }^{\mathrm{b}}$ Langfang Li, ${ }^{\mathrm{c}}$ Michi Nakata, and ${ }^{\mathrm{a}, \mathrm{f}}$ Satyendra Kumar \\ ${ }^{\mathrm{a}}$ Department of Physics and ${ }^{\mathrm{b}}$ Liquid Crystal Institute, Kent State University, Kent, Ohio, 44242 \\ cDepartment of Physics, University of Colorado, Boulder, CO 80309 \\ ${ }^{\mathrm{d} B r o o k h a v e n ~ N a t i o n a l ~ L a b o r a t o r y, ~ U p t o n, ~ N Y ~} 11973$ \\ eArgonne National Laboratory, Argonne, IL 60439 \\ ${ }^{\mathrm{f}}$ Division of Materials Research, National Science Foundation \\ 4201 Wilson Blvd., Arlington, VA 22230
}

\section{Supporting Information}

This work was supported, in part, by the National Science Foundation grant DMI-0423619 and by the Ohio Board of Regents' Research Challenge award. Use of the Advanced Photon Source (APS) was supported by the U.S. Department of Energy (DOE), Basic Energy Sciences (BES), Office of Science, under Contract No. W-31-109-Eng-38. The Midwestern Universities Collaborative Access Team's (MUCAT) sector at the APS is supported by the U.S. DOE, BES, Office of Science, through the Ames Laboratory under Contract No. W-7405-Eng-82. PNC/XOR facilities at the Advanced Photon Source, and research at these facilities, are supported by the US Department of Energy - Basic Energy Sciences, a major facilities access grant from NSERC, the University of Washington, Simon Fraser University, the Pacific Northwest National Laboratory and the Advanced Photon Source. Use of the Advanced Photon Source is also supported by the U. S. Department of Energy, Office of Science, Office of Basic Energy Sciences, under Contract DE-AC02-06CH11357. 


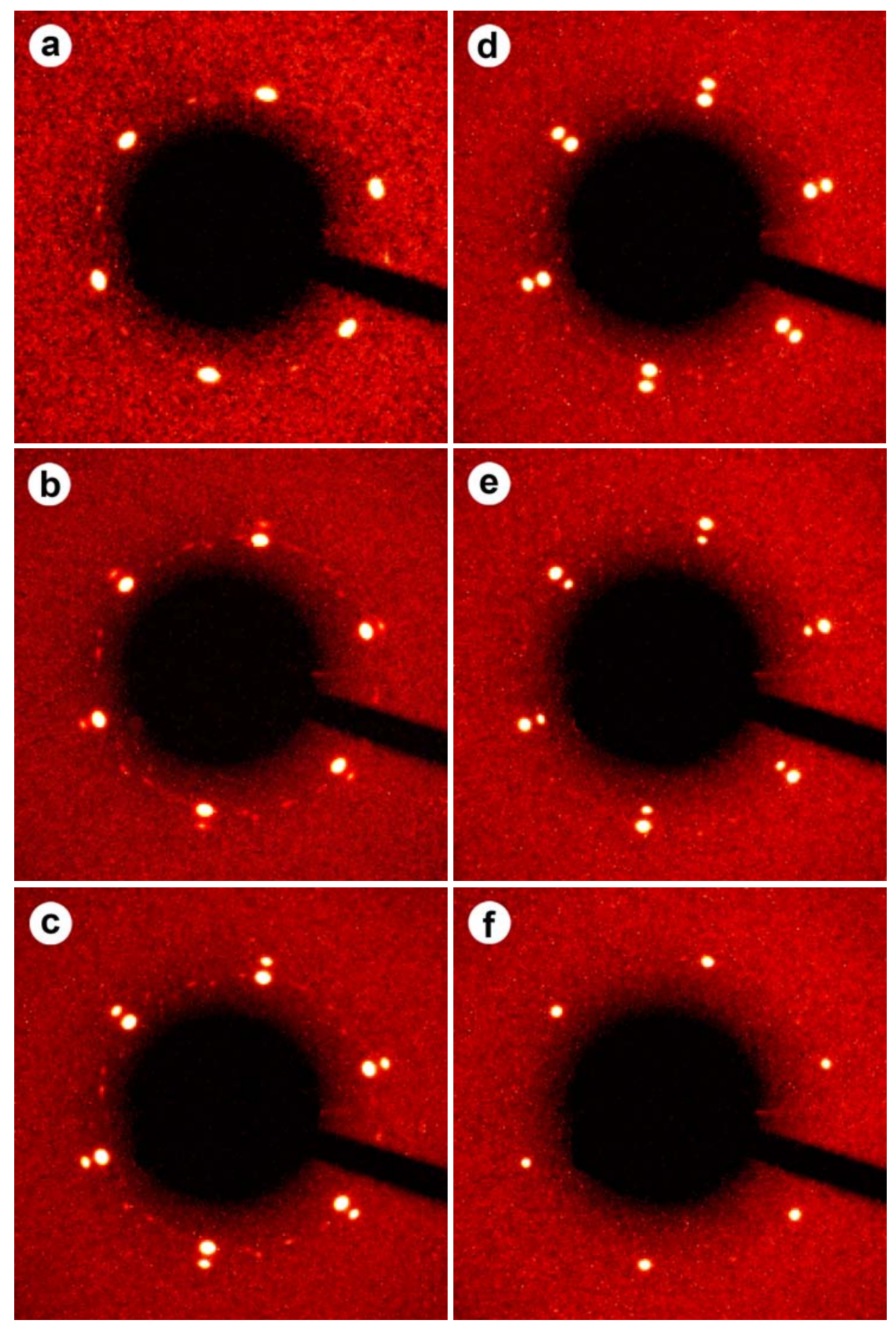

Figure S1: Coexistence of the $C_{h o}$ and $C_{h}$ LC patterns for sample C16. The coexistence was observable only during heating from the $\mathrm{C}_{\text {ho }}$ phase. The patterns were taken from the same microdomain at various temperatures while $8.0 \mu \mathrm{m}$ cell was heated to LC phase: (a) $75.0^{\circ} \mathrm{C}$, (b) $98.0^{\circ} \mathrm{C}$, (c) $100.0^{\circ} \mathrm{C}$, (d) $103.0^{\circ} \mathrm{C}$, (e) $106.0^{\circ} \mathrm{C}$, and (f) $109^{\circ} \mathrm{C}$. The orientation of hexagonal pattern retains the same direction during the transition while the d-spacing changes in discontinuous manner. 


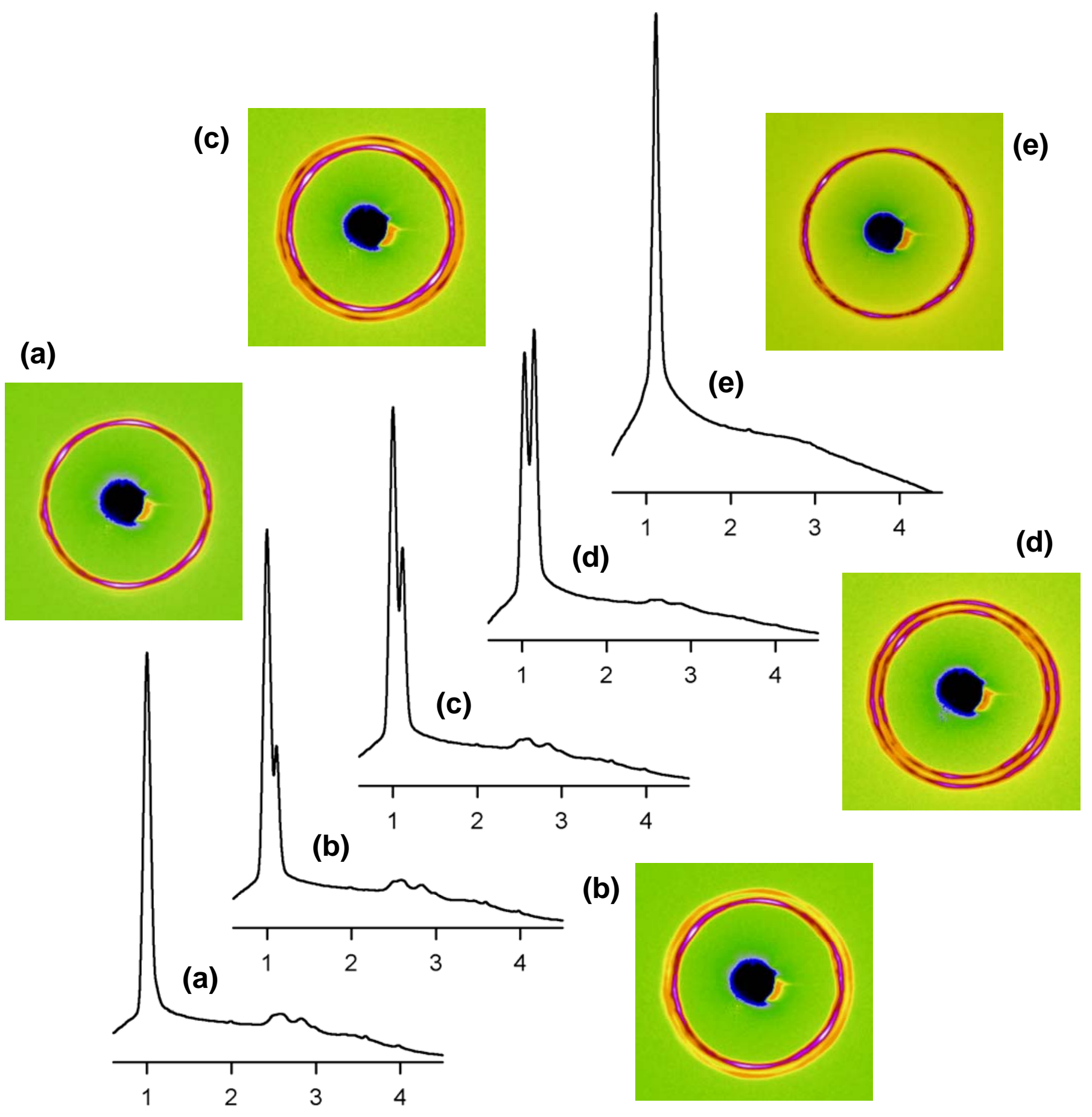

Figure S2: Coexistence of the $\mathrm{C}_{h}$ and $\mathrm{C}_{\mathrm{h}}$ patterns for compound C14. The patterns were taken from the powder sample at various temperatures during the transition from PC to LC phase: (a) $121.0^{\circ} \mathrm{C}$, (b) $125.0^{\circ} \mathrm{C}$, (c) $127.0^{\circ} \mathrm{C}$, (d) $129.0^{\circ} \mathrm{C}$, and (e) $131.0^{\circ} \mathrm{C}$. The transitional behavior is very similar to the sample $\mathbf{C 1 6}$ as described above. 

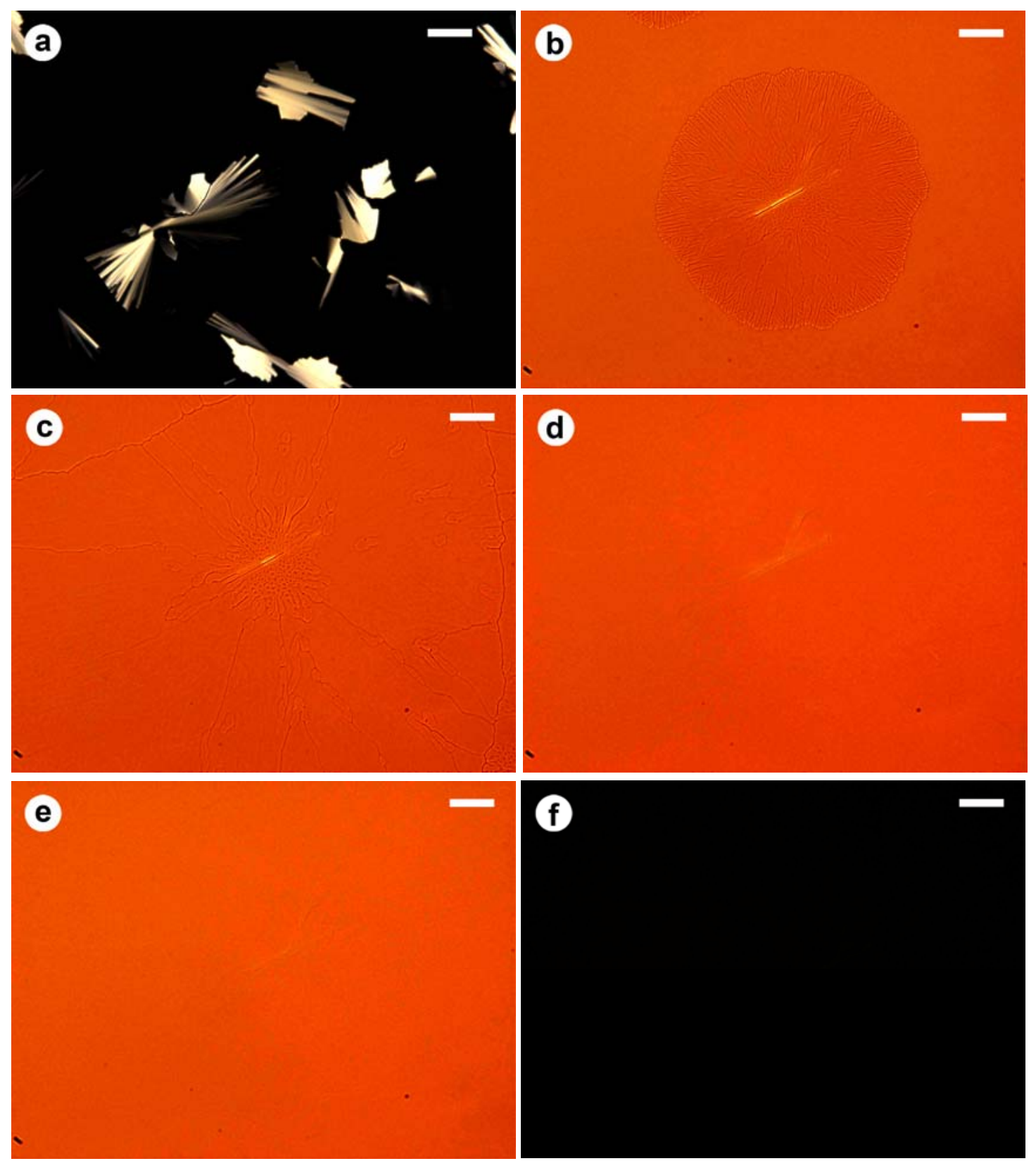

Figure S3: Optical textures formed by different thermal treatments for compound C14 in a $1.8 \mu \mathrm{m}$ cell. (a) The fast cooling from isotropic phase to $125.0{ }^{\circ} \mathrm{C}$ induces more defective domains where the column axes are planar or tilted from surface normal. (b-f) displays the formation of homeotropic texture in macroscopic scale. The slow cooling induces a selective nucleation and growth of homeotropic domain (b and c at $135.0^{\circ} \mathrm{C}$ ) and hence yielded uniform homeotropic state of hexagonal columns at lower temperatures (d at $131.0^{\circ} \mathrm{C}$ and e at $96.0{ }^{\circ} \mathrm{C}$ ), confirmed by the (f) totally dark optical texture recorded under crossed polarizers at $96.0^{\circ} \mathrm{C}$. The images were taken at (a, f) $90^{\circ}$ and (b-e) $70^{\circ}$ angles between polarizers. The scale bar corresponds to $50 \mu \mathrm{m}$. 

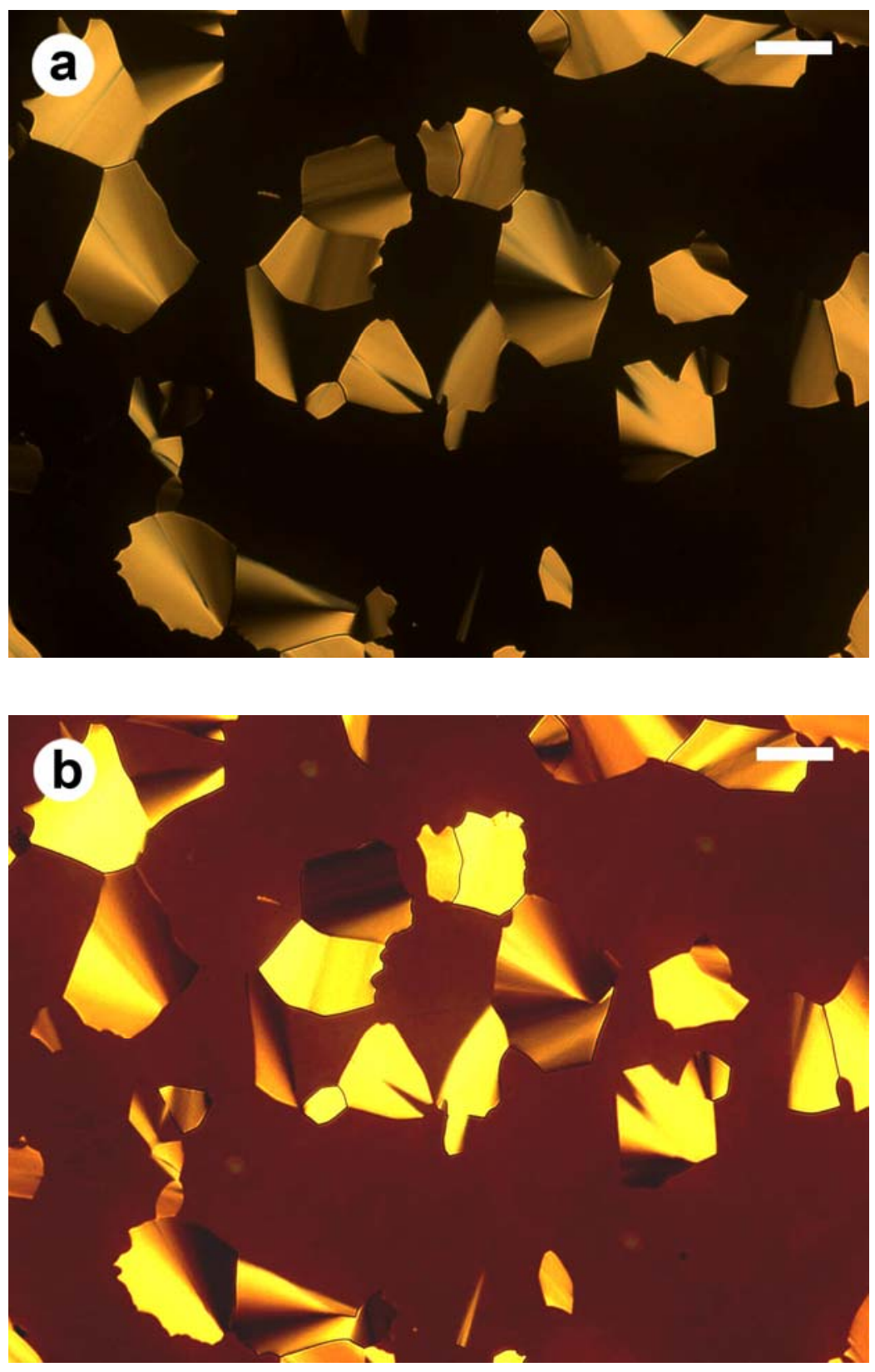

Figure S4: Polarizing optical images for fast cooling of the sample $\mathbf{C 1 2}$ in a $1.8 \mu \mathrm{m}$ cell. The fast cooling from isotropic to room temperature resulted in many bright domains, where the optic axis is planar or tilted. The dark area in (a) corresponds to the homeotropic state of columns. The images were taken at (a) $90^{\circ}$ and (b) $70^{\circ}$ angles between polarizers. The scale bar corresponds to $50 \mu \mathrm{m}$. 

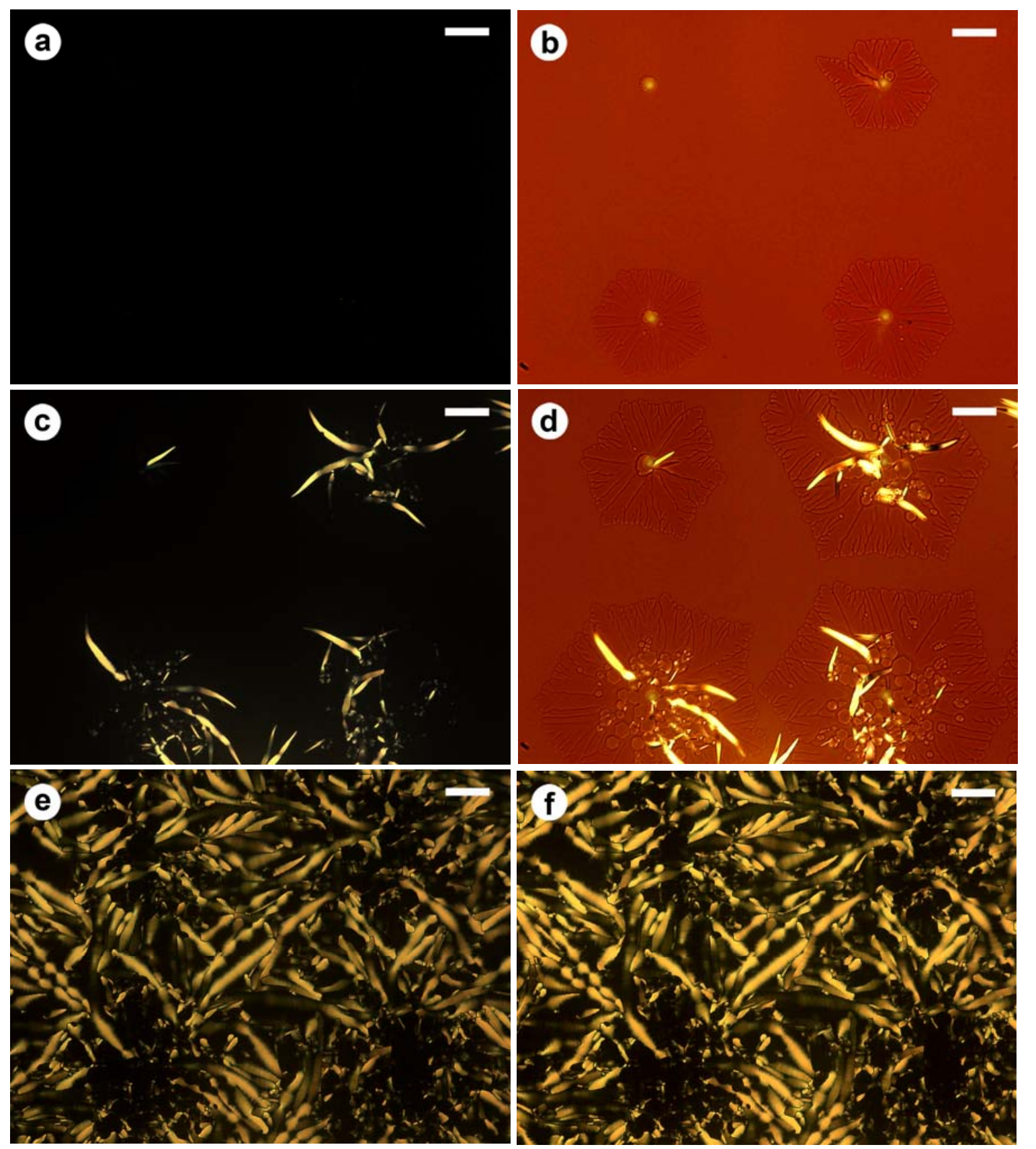

Figure S5: Optical textures for sample C12 in $1.8 \mu \mathrm{m}$ cell with slow cooling $\left(0.1^{\circ} \mathrm{C} / \mathrm{min}\right)$. The slow cooling initiates the growth of homeotropic domains as seen in (a-b). The birefringent domains start appearing at homeotropically aligned dark area (c-d) and occupied whole sample at low temperature as shown in (e) LC phase at $138.0{ }^{\circ} \mathrm{C}$ and (f) PC phase at $25.0^{\circ} \mathrm{C}$. The images were taken at (a, c, e, f) $90^{\circ}$ and (b,d) $70^{\circ}$ angles between polarizers. The scale bar corresponds to $50 \mu \mathrm{m}$. 

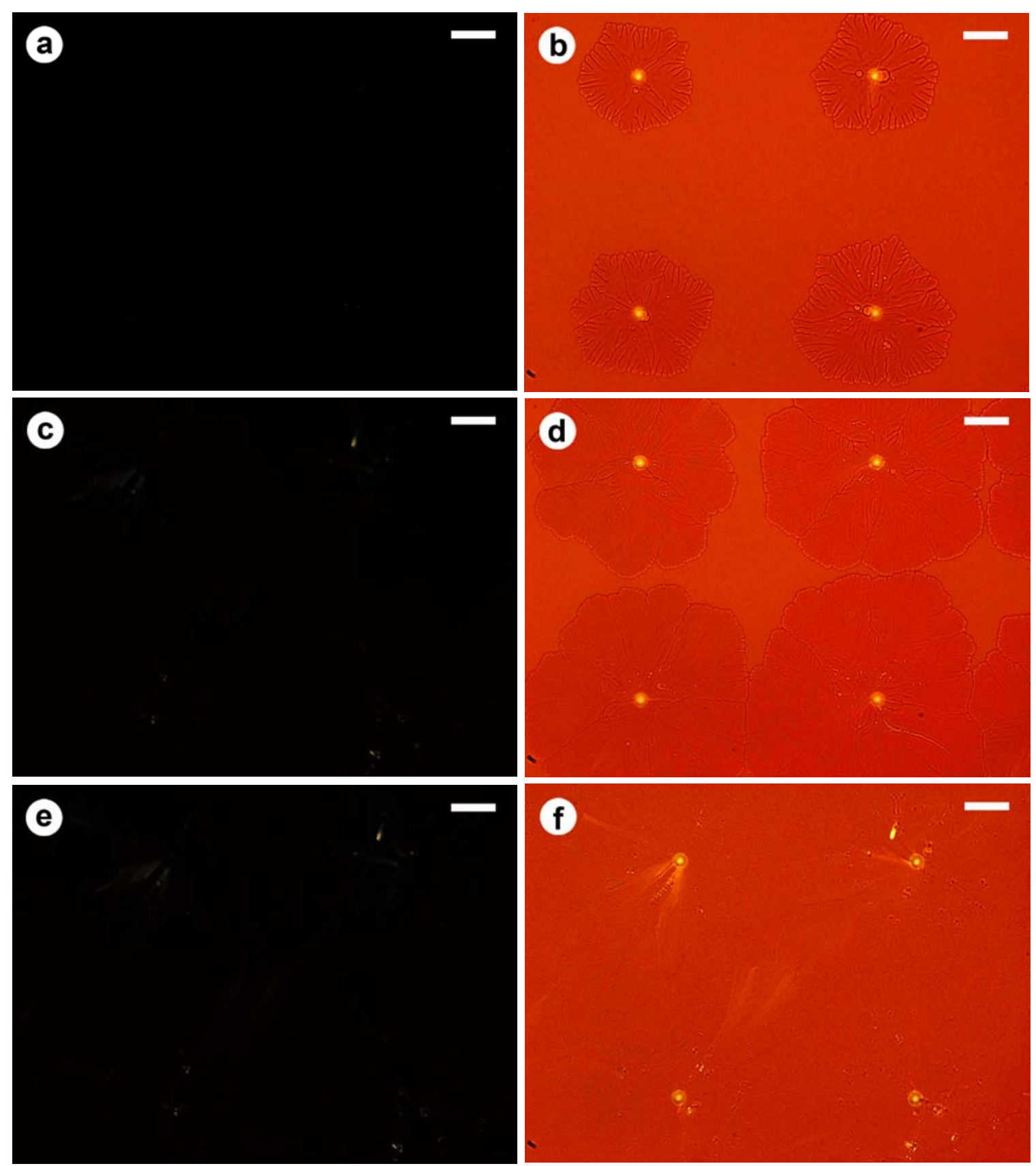

Figure S6: The uniform homeotropic texture achieved by the combination of slow and fast cooling of sample C12 in a $1.8 \mu \mathrm{m}$ cell. The fast cooling after slow nucleation of homeotropic domains near the transition prevents the formation of birefringent domains and thus can form a uniform homeotropic state in a macroscopic scale. The images were taken at (a, c, e) $90^{\circ}$ and (b,d,f) $70^{\circ}$ angles between polarizers. The scale bar corresponds to $50 \mu \mathrm{m}$. 